\title{
Motor impairment in children with autistic spectrum disorder and in children with attention deficit hyperactivity disorder
}

\author{
Maria Pia Bucci ${ }^{1 *}$, Nathalie Goulème ${ }^{1,2}$, Coline Stordeur ${ }^{3}$, Eric Acquaviva ${ }^{3}$, Mathilde Septier ${ }^{3}$, Aline Lefebvre ${ }^{3}$, \\ Hugo Peyre ${ }^{3,4,5}$, Richard Delorme ${ }^{3,4,5}$ \\ IUMR 1141 Inserm - Paris Diderot University. Robert Debré Hospital, Paris, France \\ ${ }^{2}$ Lyon Neuroscience Research Center (Inserm U1028 CNRS UMR5292), Lyon, France \& Department of Audiology and Otoneurological Evaluation, Civil Hospi- \\ tals of Lyon, Lyon, France \\ ${ }^{3}$ Child and Adolescent Psychiatry Department, Robert Debré Hospital, Paris, France \\ ${ }^{4}$ Paris Diderot University, Paris 7, France \\ ${ }^{5}$ High Functioning Autism Expert Centre, Fondamental Foundation, Paris, France
}

Article Info

\section{Article Notes}

Received: September 22, 2017

Accepted: October 24, 2017

\section{*Correspondence:}

Dr. Maria Pia Bucci, UMR 1141 Inserm - Robert Debré

Hospital, 48 Bd Sérurier, 75019 Paris, France.

E-mail address: maria-pia.bucci@inserm.fr

C 2017Bucci MP. This article is distributed under the terms of the Creative Commons Attribution 4.0 International License.

\section{Keywords}

Autistic Spectrum Disorder

ADHD

Children

Cerebellum

Postural Control

\section{ABSTRACT}

We summarize postural instabilities in children with autistic spectrum disorder (ASD) and in children with attention deficit hyperactivity disorder (ADHD), and we reported behavioral results suggesting poor cerebellar integration. We conclude that postural measures could be a promising method with which to indirectly observe cerebellar performance in children developmental disabilities such as ASD and/or ADHD.

\section{Introduction}

Postural control relies upon multiple sources of sensory information from the visual, vestibular, and somatosensory afferents $^{1}$. It is also well known that various structures in the central nervous system, such as the basal ganglia, the brainstem, the cerebellum, and several cortical areas are involved in postural control $^{2}$. To reach a postural stability during everyday life in the natural environment subject needs to weigh all these information and a deficit in one of these inputs may lead to an imbalance in other sensory inputs and may lead to postural instability.

In3 1992, Kohen-Raz ${ }^{3}$ and collaborators were the first to record postural stability in children with autistic spectrum disorder (ASD) using a platform and they reported that children with ASD were significantly more unstable than control children. A synthesis and meta-analysis of deficits in motor control in children with ASD was done by ${ }^{4}$ and several other studies ${ }^{5-10}$ observed postural instability in children with ASD. Furthermore, with altered somatosensory inputs (i.e. a sway-reference surface, or standing on foam or wearing a vibrating device around the neck region) children with ASD reported poor postural control with respect to TD children ${ }^{3,4,5,12,13,14}$.

All these reports are in line with the hypothesis that a deficit in multimodal sensory integration, in other words poor ability to reweight sensory inputs could be at the origin of such motor impairment in children with ASD.

Inline with thishypothesis, other researchers proposedaninternal 
modeling deficit for children with neurodevelopmental disabilities (for instance, in children with Developmental Coordination Disorder as reported from ${ }^{15}$. This idea, proposed firstly by ${ }^{16}$ Morasso et al. (1999) is based on the hypothesis that internal models allow stability to the body by predicting the movements before that sensori-motor feedbacks are available. Dysfunctions to this mode of motor control could severely affect motor learning capabilities in these patients that it could be most likely due to parietocerebellar abnormalities as suggested by ${ }^{17}$.

Motor problems occur in 30-50\% of children with Attention deficit hyperactivity disorder (ADHD) ${ }^{18}$. ADHD is associated with poor gross and fine motor control abilities $^{19,20,21}$ and several studies from our ${ }^{22,23}$ and other groups $^{24,25,26}$ reported postural instability in ADHD children compared to control children. In more details, the velocity of the center of pressure was found significantly higher in children with ADHD than in control children group ${ }^{24,25}$. Interestingly, postural deficits was found to be even more pronounced when children were tested in more difficult conditions, such as when their eyes were closed and/or by manipulating the visual surround response $\mathrm{e}^{26,27,28}$.

A recent study of ${ }^{29}$ found out, for the first time, a positive correlation between postural sway and cerebellar gray matter volume in adults with ADHD, providing additional support for cerebellar involvement in ADHD.

Note also that as reported by ${ }^{30}$ in a recent review, cerebellar deficiencies have been found in several developmental disorders (autism, dyslexia, ADHD); She suggested that deficits in different cerebellar subregions related to poor specific cerebro-cerebellar circuits could lead to the behavioral symptoms at both motor and cognitive levels observed in these types of children.

In the present study we wonder to explore further postural capabilities in children with ASD and ADHD and to compare these results with those reported in a group of typically developing children.

\section{Methods}

\section{Subejcts}

Here, we reported a study in which we compared postural capabilities in three different groups of twentyfive children sex-, IQ-and age-matched (mean age: $10.5 \pm$ 0.4 years): group 1, children with ASD; group 2, children with ADHD and group 3, typically developing children by using the Multitest Equilibre, also called Balance Quest, from Framiral ${ }^{\circledR}$ (www.framiral.fr), which permits to analyze the Center of Pressure (CoP) both in the spatial and temporal domains.

Children were enrolled in the study at the Child and Adolescent Psychiatry Department, Robert Debré Hospital
(Paris, France). Their neurological examination was in the normal range and they were naïve of psychotropic treatment. All children examined had the intelligence quotient (IQ) in the normal range (between 85 and 115). The diagnosis of ASD and ADHD was done according to DSM-5 criteria $^{31}$.

\section{Postural recording}

The Multitest Equilibre test, from Framiral $®$ records the displacement of the CoP sampled at $40 \mathrm{~Hz}$. Several studies from our ${ }^{32,22,23}$ and other groups $s^{33,34}$ used this system to objectively record postural sway.

A wavelet non-linear analysis using Morlet waves was applied to CoP displacements in order to elaborate a time-frequency chart of body sways ${ }^{33,35}$. Such analysis allows revealing temporal fluctuations in the body sway spectrum and the postural instability indices (PII) were measured which quantifies the postural performance by taking into account the spectral power index (PI) and the cancelling time (CT); it was calculated as follows: $\mathrm{PII}=\Sigma \mathrm{x}$ $\Sigma$ y PI (F1, F2, F3)/CT (F1, F2, F3), where PI and CT are the spectral power index and cancellation time for each of the three frequency bands (F1, low; F2, medium; F3 high frequency band, $\operatorname{see}^{36}$ ). Note that this parameter is a global postural index used during routine test by clinicians and allowing an easy and quick evaluation of the child's postural instability. The larger is the PII, the greater is the instability.

\section{Procedure}

The child was placed on the Framiral ${ }^{\circledR}$ platform in a dark room and he/she was positioned with the feet aligned in parallel on the footprints, and the arms hanging along the body. The postural recording was performed on both a stable (S) and an unstable (U) platform, under two different visual conditions: eyes open (EO) and eyes closed (EC). The child was asked to stay as stable as possible. During the EO condition, child had to fixate a small red light at a distance of $2.5 \mathrm{~m}$. The duration of each postural recording was 30 seconds, with a 15 -second rest period between conditions to reduce the possible effects of tiredness. The order of the conditions varied randomly across children.

\section{Results}

Figure 1 shows the PII for the different postural and visual conditions for TD, ASD and ADHD children, respectively. ANOVA reported a significant group effect $\left(\mathrm{F}_{(2,72)}=18.67\right.$, $\left.\mathrm{p}<2.9 \times 10^{-7}, \eta^{2}=0.34\right)$ a postural and visual condition effect $\left(\mathrm{F}_{(1,72)}=68.91, \mathrm{p}<5.1 \times 10^{-12}, \eta^{2}=0.49\right.$ and $\mathrm{F}_{(1,72)}=31.69$, $\mathrm{p}<3.2 \times 10^{-7}, \eta^{2}=0.31$ ) respectively). Interestingly, the PII was significantly larger in ASD and ADHD children with respect to $\mathrm{TD}$ children, but these values were similar in the two groups of children with ASD and with ADHD. 


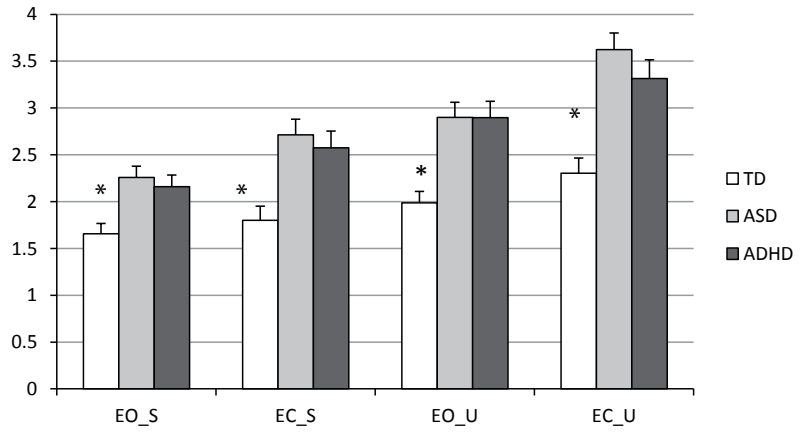

Figure 1: Mean \pm standard error of the Postural Instability Indices for the three groups of children (TD, ASD and ADHD) in the different postural and visual conditions tested. EO_S = eyes open on stable platform; EC_S = eyes closed on stable platform; EO_U = eyes open on unstable platform; EC_U = eyes closed on unstable platform. Asterisks indicate statistically difference of TD with respect ASD and ADHD groups.

\section{Discussion}

As reported by the PII measures, children with ASD and children with ADHD show a similar instability and a common postural pattern: the Postural Instability Indices are larger, particularly when vision is not present on an unstable platform with respect to those observed in TD children. Note also that, in contrast to Sjöwall's report ${ }^{37}$, given the small variability of the data observed in our patients, postural control was poor in all children examined.

Such body instability reported in children with neurodevelopmental disorders could be due to their impairment to use adaptive mechanisms to compensate/ reweigh sensorial inputs as hypothesized by ${ }^{38}$ this deficit is more pronounced when children are tested in difficult conditions (for instance, when eyes are closed and when the platform is unstable). Indeed, it is well known that healthy children are more instable in a such conditions, most likely due to their difficulty to compensate with other sensorial inputs $\mathrm{see}^{32}$. We advanced the hypothesis that such difficulty could be more important in children with neurodevelopmental disorders than in TD children.

Recall that the cerebellum is involved in motor learning and motor control, and patients with cerebellar tumors showed large instability with respect to healthy subjects, particularly in deprived sensory conditions ${ }^{39,26}$. It has also been reported that cerebellar activity increased during standing posture ${ }^{40,41}$ and a recent study by ${ }^{42}$, using a transcranial direct current stimulation applied over the cerebellum, also showed a direct effect of the cerebellum on postural control. Based on these findings and Stoodley's report (2016) previously cited, we suggest that the poor postural control observed in children with autism and hyperactivity could be due to cerebellar impairment and deficiencies in cerebrocortical network, leading to abnormal instability. On the other hand we could not exclude that other parts of the brain (as basal ganglia, brain stem, cortical areas), and sensory nerves are also deficient in these patients.

${ }^{43}$ suggested that postural abnormalities in children with neurodevelopmental disorders could result from impaired cortico-striatal loops and/or cortico-cerebellar loops more than cerebellar structural abnormalities. We agree with this hypothesis and in order to definitely establish the location of the deficit further imaging studies during postural tasks in children with neurodevelopmental disorders are needed. Interestingly, a recent study of ${ }^{44}$ in children with ADHD reported a deficit in postural sway that was correlated to a decreased brain connectivity from the cerebellum to the premotor and the anterior cingulate cortex.

It is also well known that the cerebellum is under adaptive mechanisms and few studies in patients exist showing cerebellar plasticity after postural training. ${ }^{45}$ observed that in 20 patients with cerebellar degeneration, two weeks of sensorimotor training lead to both an improvement in postural performances and an increase of gray matter volume in the cerebellum and in dorsal premotor cortex; in a group of patients with Parkinson's disease ${ }^{46}$ reported a change of grey matter in the right cerebellum, together with an improvement in postural stability after postural training on movable support. Recently, ${ }^{47}$ examined the effect of eight weeks of balance training program in a group of 29 children with traumatic brain injury and they found that the changes in balance control were associated with alterations in the cerebellar white matter microstructure. Future research on postural training in children with neurodevelopmental disorders combined with imaging studies for measuring the corticocerebellar activity could be useful to gain more insight on such issue.

Finally, as shown here, we believe that postural measures could be a promising objective method with which to indirectly observe cerebellar performance in children with neurodevelopmental disorders.

\section{References}

1. Brandt T. Vertigo: its multisensory syndromes. Springer New York. 2003.

2. Mergner T, Rosemeier T. Interaction of vestibular, somatosensory and visual signals for postural control and motion perception under terrestrial and microgravity conditions-a conceptual model. Brain Res Brain Res Rev. 1998; 28: 118-135.

3. Kohen-Raz R, Volkmar FR, Cohen DJ. Postural control in children with autism. J Autism Dev Disord. 1992; 22(3): 419-32.

4. Gepner B, Mestre DR. Brief Report: Postural Reactivity to Fast Visual Motion Differentiates Autistic from Children with Asperger Syndrome. Journal of Autism and Developmental Disorders. 2002; 32(3): 231-238.

5. Molloy CA, Dietrich KN, Bhattacharya A. Postural stability in children 
with autism spectrum disorder. Journal of Autism Developmental Disorder. 2003; 33(6): 643-652.

6. Minshew NJ, Sung, K, Jones B, et al. Underdevelopment of the postural control system in autism. Neurology. 2004; 63(11): 2056-2061.

7. Ming X, Brimacombe M, Wagner GC. Prevalence of motor impairment in autism spectrum disorders. Brain and Development. 2007; 29(9): 565-570.

8. Fournier KA, Kimberg CI, Radonovich KJ, et al. Decreased static and dynamic postural control in children with autism spectrum disorders. Gait Posture. 2010; 32(1): 6-9. doi: 10.1016/j.gaitpost.2010.02.007

9. Memari AH, Ghanouni P, Shayestehfar et al. Effects of visual search vs. auditory tasks on postural control in children with autism spectrum disorder. Gait \& Posture. 2013; 39(1): 229-234.

10. De Schipper E, Mahdi S, de Vries P, et al. Functioning and disability in autism spectrum disorder: A worldwide survey of experts. Autism Research. 2016; 9(9): 959-969.

11. Wang Z, Hallac RR, Conroy KC, et al. Postural orientation and equilibrium processes associated with increased postural sway in autism spectrum disorder (ASD). J Neurodev Disord. 2016; 8: 43. eCollection 2016.

12. Doumas M, McKenna R, Murphy B. Postural control deficits in autism spectrum disorder: The role of sensory integration. J Autism Dev Disord. 2015; 46(3): 853-861.

13. Morris SL, Foster CJ, Parsons R, et al. Differences in the use of vision and proprioception for postural control in autism spectrum disorder. Neuroscience. 2015; 307: 273-280. doi: 10.1016/j. neuroscience.2015.08.040

14. Smoot Reinert S, Jackson K, Bigelow K. Using Posturography to Examine the Immediate Effects of Vestibular Therapy for Children with Autism Spectrum Disorders: A Feasibility Study. Phys Occup Ther Pediatr. 2015; 35(4): 365-380.

15. Adams IL, Lust JM, Wilson PH, et al. Compromised motor control in children with DCD: a deficit in the internal model?-A systematic review. Neuroscience \& Biobehavioral Reviews. 2014; 47: 225-244.

16. Morasso P, Casadio M, Mohan V, Rea F, Zenzeri J. Revisiting the bodyschema concept in the context of whole-body postural-focal dynamics. Front Hum Neurosci. 2015 Feb 17;9:83.

17. Desmurget M, Grafton S. Feedback or feedforward control: end of adichotomy. In: Johson-Frey, S.H.E. (Ed.), Taking Action: Cognitive NeurosciencePerspectives on Inentional Acts. MIT Press Cambridge MA. 2003; pp. 289-338.

18. Goulardins JB, Marques JCB, De Oliveira JA. Attention Deficit Hyperactivity Disorder and Motor Impairment. Perceptual and Motor Skills. 2017; 124(2): 425-440.

19. Piek JP, Pitcher TM, Hay DA. Motor coordination and kinaesthesis in boys with attention deficit-hyperactivity disorder. Dev. Med. Child Neurol. 1999; 41:159-165.doi:10.1017/S00121622990 00341

20. Wang HY, Huang TH, Lo SK. Motor ability and adaptive function in children with attention deficit hyperactivity disorder. Kaohsiung J Med Sci. 2011; 27: 446-452.doi:10.1016/j.kjms.2011.06.004

21. Papadopoulos N, McGinley JL, Bradshaw JL, et al. An investigation of gait in children with Attention Deficit Hyperactivity Disorder: a case controlled study. Psychiatry Res. 2014; 218: 319-323.doi: 10.1016/j. psychres.2014.04.037

22. Bucci MP, Seassau M, Larger S, et al. Effect of visual attention on postural control in children with attention-deficit/hyperactivity disorder. Research in Developmental Disabilities. 2014; 35: 1292-1300.

23. Bucci MP, Stordeur C, Acquaviva E, et al. Postural instability in children with ADHD is improved by methylphenidate. Frontiers in Child and Neurodevelopmental Psychiatry, eCollection 2016.
24. Zang Y, Gu B, Qian Q et al. Objective measurement of the balance dysfunction in attention deficit hyperactivity disorder children. Chin J Clin Med. 2002; 6: 1372-1374.

25. Wang J, Wang Y, Ren Y. A case control study on balance function of attention deficit hyperactivity disorder (ADHD) children. J Peking Univ Health Sci. 2003; 35: 280-283.

26. Buderath P, Gartner K, Frings M, et al. Postural and gait performance in children with attentiondeficit/hyperactivity disorder. GaitPosture. 2009; 29: 249-254.doi: 10.1016/j.gaitpost.2008.08.016

27. Shum SBM, Pang MYC. Children with attention deficit hyperactivity disorder have impaired balance function: involvement of somatosensory, visual, and vestibular systems. J Pediatr. 2009; 155(2): 245-249.

28. Hassan DM, Azzam H. Sensory integration in attention deficit hyperactivity disorder: implications to postural control. In: JM Norvilit (Ed.), Contemporary Trends in ADHD Research. InTech Rijeka Croatia. 2012; pp. 1-12.

29. Hove MJ, Zeffiro TA, Biederman J, et al. Postural sway and regional cerebellar volume in adults with attention-deficit/hyperactivity disorder. Neuroimage Clin. 2015 May 21; 8: 422-8. doi: 10.1016/j. nicl.2015.05.005. eCollection 2015.

30. Stoodley CJ. The Cerebellum and Neurodevelopmental Disorders. Cerebellum. 2016; 15(1): 34-7. doi: 10.1007/s12311-015-0715-3.

31. American Psychiatric Association. Diagnostic and Statistical Manual of Mental Disorders 5 ${ }^{\text {th }}$ Edn. 2013.

32. Goulème N, Ezane MD, Wiener-Vacher S, et al. Spatial and temporal postural analysis: a developmental study in healthy children International Journal of Developmental Neuroscience. 2014; 38C:169177.

33. Dumistrescu M, Lacour M. Nouveaux critères quantitatifs d'analyse du contrôle postural. In: Pérennou D, Lacour M, editors. Efficience et déficiences du contrôle postural. Marseille Solal éditeur. 2006 ; p. 65-75.

34. Lacour M, Bernard-Demanze L, Dumitrescu M. Posture control, aging, andattention resources: models and posture analysis methods. Clin Neurophysiol. 2008; 38: 411-421.

35. Bernard Demanze L, Dumitrescu M, Jimeno P, et al. Age-related changes in posture control are differentially affected by postural and cognitive task complexity. Curr Aging Sci. 2009; 2(2): 139-49.

36. Bernard-Demanze L, Léonard J, Dumitrescu M, et al. Static and dynamic posture control in postlingual cochlear implanted patients: effects of dual-tasking, visual and auditory inputs suppression. Front Integr Neurosci. 2014; 7(111). http://dx.doi.org/10.3389/ fnint.2013.00111

37. Sjöwall D, Roth L, Lindqvist S, et al. Multiple deficits in ADHD: executive dysfunction, delay aversion, reaction time variability, and emotional deficits. Journal of Child Psychology and Psychiatry. 2013; 54(6): 619-627.

38. Assländer L, Peterka RJ Sensory reweighting dynamics in human postural control. J Neurophysiol. 2014; 111: 1852-1864. doi:10.1152/ jn.00669.2013

39. Konczak J, Schoch B, Dimitrova A, et al. Functional recovery of children and adolescents after cerebellar tumour resection. Brain. 2005; 128: 1428-1441.

40. Ouchi Y, Okada H, Yoshikawa E, et al. Brain activation during maintenance of standing postures in humans. Brain. 1999; 122: 329338.doi:10.1093/brain/122.2.329.

41. Jahn K, Deutschländer A, Stephan T, et al. Imaging human supraspinal locomotor centers in brainstem and cerebellum. Neuroimage. 2008; 39(2): 786-92. 
42. Inukai Y, Saito K, Sasaki R, et al. Influence of Transcranial Direct Current Stimulation to the Cerebellum on Standing Posture Control. Front Hum Neurosci. 2016; 10: 325. doi: 10.3389/fnhum.2016.00325. eCollection.

43. Nicolson RI, Fawcett AJ. Procedural learning difficulties: reuniting the developmental disorders. TRENDS in Neurosciences. 2007; $30(4): 135-141$.

44. Kim SM, Hyun GJ, Jung TW, et al. Balance Deficit and Brain Connectivity in Children with Attention-Deficit/Hyperactivity Disorder. Psychiatry Investig. 2017; 14(4): 452-457. doi: 10.4306/pi.2017.14.4.452
45. Burciu RG, Fritsche N, Granert 0, et al. Brain Changes Associated with Postural Training in Patients with Cerebellar Degeneration: A Voxel-Based Morphometry Study. The Journal of Neuroscience. 2013; 33(10): 4594-4604.

46. Sehm B, Tauberta M, Conde V, et al. Structural brain plasticity in Parkinson's disease induced by balance training. Neurobiology of Aging. 2014; 35: 232-239.

47. Drijkoningen D, Leunissen I, Caeyenberghs K, et al. Regional volumes in brain stem and cerebellum are associated with postural impairments in young brain-injured patients. Hum Brain Mapp. 2015; 36(12): 4897-909. doi: 10.1002/hbm.22958. 